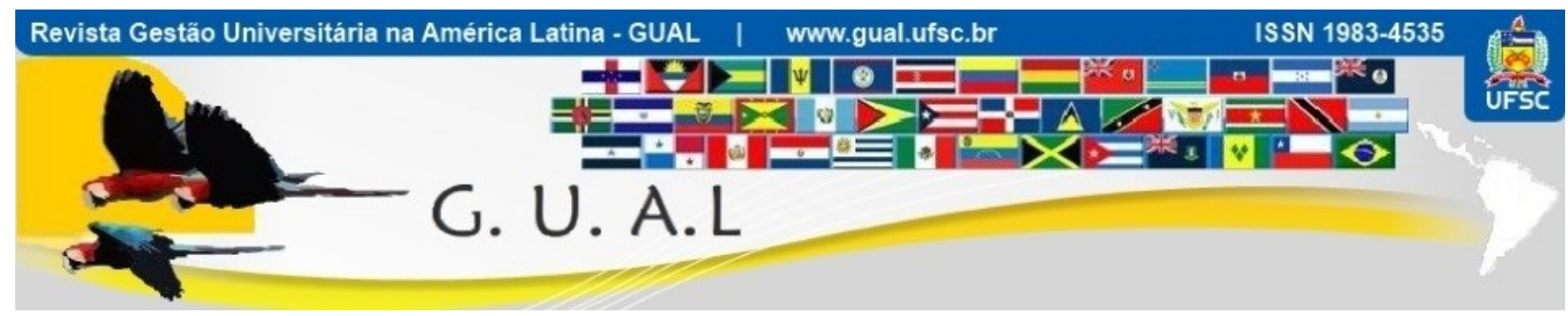

DOI: http://dx.doi.org/10.5007/1983-4535.2013v6n4p107

\title{
A IMPORTÂNCIA DA EDUCAÇÃO A DISTÂNCIA NA MELHORIA DA QUALIDADE DE VIDA
}

\section{THE IMPORTANCE OF DISTANCE EDUCATION IN ORDER TO IMPROVE THE QUALITY OF LIFE}

Eliza Regina Cordeiro, Mestranda Universidade Federal de Santa Catarina - UFSC

lizdailha@gmail.com

Andressa Sasaki Vasques Pacheco, Doutora Universidade Federal de Santa Catarina - UFSC andressa.pacheco@ufsc.br

Irineu Manoel de Souza, Doutor Universidade Federal de Santa Catarina - UFSC irineu.manoel@ufsc.br

Recebido em 29/novembro/2013

Aprovado em 29/novembro/2013

Sistema de Avaliação: Double Blind Review

Esta obra está sob uma Licença Creative Commons Atribuição-Uso. 


\begin{abstract}
RESUMO
O presente artigo tem como objetivo demonstrar a importância da Educação a Distância na melhoria da qualidade de vida do indivíduo e sua considerável contribuição para a democratização do acesso à educação superior. No trabalho são apresentados conceitos dos dois temas e enfatiza a importância da educação na promoção da qualidade de vida do homem moderno. A pesquisa foi realizada com os alunos egressos do Curso de Graduação em Administração a Distância da Universidade Federal de Santa Catarina do polo presencial de Lages/SC. Foram encaminhados, por e-mail, questionários aos 29 alunos egressos do curso em questão e foram obtidas 21 respostas. Os resultados da pesquisa mostram que a conclusão do Curso de Administração a Distância propiciou aumento na faixa salarial da maioria dos respondentes. Ficou comprovado que com a aquisição de novos conhecimentos, a maioria, conseguiu trabalho ou uma progressão funcional ocorrendo ampliação da qualidade de vida dos referidos alunos após a realização do curso.
\end{abstract}

Palavras-chave: Educação a Distância. Qualidade de Vida. Educação Superior. Trabalho.

\begin{abstract}
This article aims to demonstrate the importance of Distance Education in order to improve the individuals' life quality, and its considerable contribution to the democratization of access to the higher education. In the study, it was possible to present the concepts of both topics, and also, it emphasizes the education importance in the life quality promotion of modern man. The study was conducted with former students of the Undergraduate Course on Distance Education in Business Administration of the Federal University of Santa Catarina, at the school attendance of Lages/SC. It was possible to send questionnaires, by e-mail, to the 29 students graduated from the course, and 21 responses were obtained. The research results show that the conclusion of the Distance Course on Business Administration provided an increase in the salary range of most respondents. It was proven that, with the acquisition of new knowledge, most of them were able to get a job or a career progression along with the students' life quality expansion after the course completion.
\end{abstract}

Keywords: Education. Quality of life. Higher Education. Work. 


\section{INTRODUÇÃO}

A expressão qualidade de vida foi apropriada pelo senso comum como forma de resumir melhorias ou alto padrão de bem-estar das pessoas na área social, econômica ou emocional. De acordo com Almeida, Gutierrez e Marques (2012), a qualidade de vida sempre esteve presente na sociedade, pois se remete ao interesse pela vida. Porém, o importante na vida é cada indivíduo encontrar uma boa qualidade frente às possibilidades individuais de ação a ele oferecidas.

A noção de qualidade de vida transita em um campo semântico e polissêmico: de um lado, está relacionada ao modo, às condições e aos estilos de vida. De outro, inclui as ideias de construção humana e valores socialmente constituídos. E, por fim, relaciona-se ao campo da democracia, do desenvolvimento e dos direitos humanos e sociais. (ALMEIDA; GUTIERREZ; MARQUES, 2012, p.107).

A preocupação com a qualidade de vida é uma questão que diz respeito não somente ao indivíduo, mas a sociedade como um todo, pois remete a condições de sobrevivência e de conforto de todos os sujeitos. O desenvolvimento contínuo da humanidade provoca alterações nas condições de vida em nosso planeta. As mudanças na maneira de viver provocadas pelo progresso tecnológico e as alterações introduzidas na superfície terrestre nem sempre favorecem a qualidade de vida sobre a terra. "[...] Cientes desta catastrófica defasagem entre o ideal buscado e a realidade alcançada, pensadores de todas as índoles repetem, assustados e, com certa pertinácia, a urgente palavra de ordem: melhorar a qualidade de vida!”. (FINKLER, 1994, p. 8).

As transformações tecnológicas, organizacionais e gerenciais decorrentes da sociedade globalizada que impõe a lógica da competitividade como fator fundamental nas relações econômicas estão apresentando novos desafios em todas as atividades, particularmente aos trabalhadores e às instituições educacionais. (CATAPAN, 2009; MELO; MELO; NUNES, 2009).

Nos tempos atuais, o indivíduo precisa estar em constante aprimoramento para fazer frente aos desafios impostos pela sociedade globalizada. A formação básica não é mais suficiente, já que o mundo do trabalho vem exigindo profissionais altamente qualificados.

Nesse contexto, o indivíduo é incitado ou obrigado a voltar a estudar para atender às demandas desta nova sociedade, “[...] processo que recebe diferentes denominações: 
formação continuada, educação permanente, formação ao longo da vida, mas todas com o mesmo sentido: a necessidade de aprendizagem constante". (CATAPAN, 2009, p. 30-31).

A educação, segundo Melo, Melo e Nunes (2009), permite que o homem alcance seus objetivos pessoais e junto à sociedade na qual está inserido, é fundamental para desenvolvimento da humanidade. O conhecimento proveniente dela serve de instrumento na busca por qualidade de vida, à medida que possibilita aos indivíduos a expansão e o exercício integral de suas potencialidades.

Moore e Kearsley (2007) afirmam que o crescente avanço dos recursos tecnológico, de informação e comunicação ampliou as possibilidades de acesso aos processos de ensino, principalmente tendo a internet como apoio. A Educação a Distância torna-se destaque neste processo, possuindo relevância perante a sociedade moderna, pois possibilita o ingresso de milhares de pessoas ao sistema educacional em virtude da sua autonomia de aprendizado, aliado a flexibilidade de espaço e tempo.

Para Melo, Melo e Nunes (2009), a Educação a Distância surge como ferramenta primordial em busca da qualidade de vida, diferentemente da educação presencial possibilita qualquer indivíduo que não tenha tempo ou, ainda, não pode estar fisicamente em sala possa continuar seus estudos.

Este artigo foi elaborado a partir de uma pesquisa realizada junto aos alunos egressos do Curso de Graduação em Administração a Distância do polo presencial de Lages/SC. O município de Lages está a $224 \mathrm{~km}$ distante da capital Florianópolis e possui IDH - Índice de Desenvolvimento Humano de 0,813 , considerado elevado e é a oitava cidade no ranking populacional catarinense.

O programa de ensino a distância na Universidade Federal de Santa Catarina - UFSC é uma das principais políticas de expansão e inclusão social. Envolve diferentes Unidades de Ensino, Departamentos, Cursos e Laboratórios, integrando projetos que congregam ações, condições e competências num programa de cooperação para implementar diversos cursos em nível de graduação, pós-graduação lato sensu e capacitação.

A UFSC oferece à comunidade Lageana os cursos de graduação a distância em Matemática, Física, Administração e Administração Pública.

A pesquisa visou demonstrar a importância da Educação a Distância na melhoria da qualidade de vida do indivíduo e sua contribuição para a democratização do acesso à educação superior. 
Uma pesquisa deve justificar-se pela sua importância, oportunidade e viabilidade (ROESCH, 2009).

Em relação à sua importância, justifica-se pela necessidade de demonstrar para a sociedade o importante papel do ensino a distância na democratização da educação e como recurso de opção de acesso, mais facilmente, a mais e melhores recursos de aprendizado do que no passado.

Justifica-se a oportunidade do estudo após ampla pesquisa na base de dados de dissertações e teses da Universidade Federal de Santa Catarina, e haver constatado a escassez de trabalhos acerca da referida temática.

O trabalho foi viabilizado pelo acesso da pesquisadora aos dados cadastrais dos alunos egressos do Curso de Graduação em Administração a Distância do polo presencial de Lages/SC.

\section{QUALIDADE DE VIDA E EDUCAÇÃO}

Poucas palavras no cotidiano da sociedade despertam atenção. Mas se forem considerados a evolução e os contrastes do presente, as incertezas versus as verdades científicas, as muitas e diferentes experiências vivenciadas pelo homem nas diferentes culturas, uma se destaca, algumas vezes mais com conotação quantitativa ou em outras numa perspectiva mais qualitativa. A palavra qualidade está " [...] presente na contemporaneidade, a qual pode ser articulada com a idéia de condição, de função, de atitude, de posição ou ter outro sentido em consequência da abrangência que esse tema possui”. (SIMÕES, 2001, p. 169).

A sociedade contemporânea incorporou o termo qualidade de vida ao seu linguajar, com diferentes formas de conotação. Porém, é consenso que é algo bom falar em qualidade de vida.

"O termo qualidade de vida, de fato, tem sido muito utilizado ultimamente, mas não há consenso sobre sua definição, porém é importante lembrar que a qualidade de vida tem algo de subjetivo, ou seja, próprio de pessoa para pessoa." (HEERDT, 2013, p. 1).

Heerdt (2013) relata que muitos fatores têm influência na qualidade de vida e os mais importantes dependem da própria pessoa, de sua visão do ideal, de sua herança familiar e cultural, da fase de vida no momento, sua expectativa para o futuro, suas possibilidades, do ambiente, da própria visão do mundo e da vida, dos seus relacionamentos, etc. 
Para Almeida, Gutierrez e Marques (2012, p. 20-21), a perspectiva objetiva acerca da qualidade de vida se caracteriza como

[...] uma busca por dados quantitativos e qualitativos que permitam traçar um perfil de um indivíduo ou grupo em relação ao seu acesso a bens e serviços. Esses dados são gerados com base em informações globais dos grupos estudados. A partir deles, são traçados índices estatísticos de referência sobre posições sócioeconômicas de populações, assim como comparações entre objetos diferentes. Com esse tipo de tratamento, torna-se possível estabelecer quadros de perfis socioeconômicos para ações voltadas à melhoria da qualidade de vida dos sujeitos envolvidos.

A compreensão acerca da qualidade de vida e seus indicadores na esfera objetiva se torna necessária como instrumento de avaliação das condições de vida de populações, para indicação de áreas de carência de serviços e/ou assistência e, também, como “[...] base para caracterização dos grupos em relação aos ambientes socioeconômicos em que estão inseridos". (ALMEIDA; GUTIERREZ; MARQUES, 2012, p. 27).

Entretanto, qualidade de vida não se dissipa nas condições objetivas de que dispõe uma pessoa, tampouco no tempo de vida que possa ter, mas no significado dado a essas condições e na sua maneira de viver.

Almeida, Gutierrez e Marques (2012, p. 21), afirmam que a análise da qualidade de vida sob um aspecto subjetivo leva em conta,

[...] questões de ordem concreta, porém, considera variáveis históricas, sociais, culturais e de interpretação individual sobre as condições de bens materiais e de serviços do sujeito. Não busca uma caracterização dos níveis de vida apenas sobre dados objetivos; relaciona-os com fatores subjetivos e emocionais, expectativas e possibilidades dos indivíduos ou grupos em relação às suas realizações, e a percepção que os atores têm de suas próprias vidas, considerando, inclusive, questões imensuráveis como prazer, felicidade, angústia e tristeza.

Neste final de milênio fala-se em da qualidade de vida associada à obtenção de saúde, condições dignas de trabalho, direito à moradia, alimentação adequada, uma educação de qualidade, liberdade política, segurança, lazer, prática de atividades físicas, esporte, meio ambiente, vida longa, etc. (SIMÕES, 2001).

A obsessão com busca de qualidade de vida diz respeito a toda a sociedade, "[...] pois remete a condições de sobrevivência e de conforto de todos os sujeitos". (ALMEIDA; GUTIERREZ; MARQUES, 2012, p. 36).

A qualidade de vida pode ser definida como 
[...] a soma das condições econômicas, ambientais, científico-culturais e políticas coletivamente construídas e postas à disposição dos indivíduos para estes possam realizar suas potencialidades: inclui a acessibilidade à produção e ao consumo, aos meios para produzir cultura, ciência e arte, bem como pressupõe a existência de mecanismos de comunicação, de informação, de participação e de influência nos destinos coletivos, através da gestão territorial que assegure água e ar limpos, higidez ambiental, equipamentos coletivos urbanos, alimentos saudáveis e a disponibilidade de espaços naturais amenos urbanos, bem como da preservação de ecossistemas naturais. (HERCULANO, 2000, p. 22).

Segundo Silva e Marchi (1997), existem três "modalidades" de estresse que interferem na qualidade de vida: ambiental, familiar e ocupacional. O estresse ambiental está relacionado à vida em sociedade: instabilidade da economia, falta de segurança, briga e divergências com vizinhos, etc. $\mathrm{O}$ estresse familiar refere-se às tensões resultantes de conflitos no ambiente familiar. $\mathrm{O}$ estresse ocupacional está relacionado às tensões decorrentes do trabalho e da vida profissional. É o mais emblemático na atualidade, se considerarmos que é trabalhando que passamos grande parte da vida quando estamos acordados e que no trabalho ou através dele alcançaremos a maioria de nossos ideais.

“À medida que se sente valorizado e dignificado ao trabalhar, o empregado não somente se compromete, mas melhora o grau de satisfação em relação a seu trabalho. Reduzse, assim o estresse ocupacional, e melhora sua qualidade de vida." (SILVA; MARCHI, 1997, p. 90).

A sociedade moderna, todavia exige um cidadão capaz de estar à sua frente, comandando o processo exponencial de inovação, não correndo atrás, como se fora sucata. Enfrentar desafios novos, avaliar os contextos sóciohistóricos, filtrar informação, manter-se permanentemente em processo de formação são responsabilidades inalienáveis para quem procura ser sujeito de sua própria história, não massa de manobra para sustentar privilégios alheios. (DEMO, 2007, p. 32).

A educação será, cada vez mais, o espaço e o indicador fundamental de qualidade, “[...] porque representa a estratégia básica da formação humana”. (DEMO, 2007, p. 20).

Novos desafios estão sendo apresentados em todas as atividades, particularmente aos trabalhadores e às instituições educacionais, decorrentes das transformações tecnológicas, organizacionais e gerenciais do mundo moderno. (CATAPAN, 2009).

De acordo com Melo, Melo e Nunes (2009), as relações econômicas na sociedade moderna e globalizada são determinadas pela competitividade. Diante dessa afirmativa, o exercício profissional no intricado e obscuro mundo do trabalho, vêm exigindo do trabalhador 
conhecimentos provenientes de um sistema que incuta à dinâmica da conectividade. "O conhecimento é decisivo para a cidadania e para a competitividade.” (DEMO, 2007, p. 25).

A formação básica não é mais suficiente, o indivíduo é estimulado ou obrigado a completar seus estudos diante das transformações do mundo do trabalho. Processo este denominado de "[...] formação continuada, educação permanente, formação ao longo da vida, mas todas com o mesmo sentido: a necessidade de aprendizagem constante". (CATAPAN, 2009, p. 30-31).

O conhecimento procedente da educação serve de instrumento para que os indivíduos se desenvolvam para exercerem completamente suas potencialidades. Na atualidade, segundo Melo, Melo e Nunes (2009, p. 281), “[...] as empresas esperam por saberes multidisciplinares, que estejam intercalados e fundamentados na formação oriunda da vida acadêmica, mas que possam ser adicionados às experiências vivenciadas".

À medida que se sente valorizado e dignificado ao trabalhar, o empregado não somente se compromete, mas melhora o grau de satisfação em relação a seu trabalho. Reduzse, assim o estresse ocupacional, e melhora sua qualidade de vida.

A educação superior, segundo Melo, Melo e Nunes (2009), tem assumido papel de destaque por sua contribuição no crescimento econômico, no desenvolvimento cultural da sociedade e, sobretudo, por seu papel no desenvolvimento da humanidade. O surgimento da Educação a Distância “[...] é um marco que não pode ser ignorado e certamente traz para a humanidade uma aceleração acentuada para a construção de uma vida melhor para milhões de seres humanos, não importando onde estejam". (SILVA, 2007, p. 6).

A Educação a Distância “[...] nasceu e se desenvolveu como resposta a um acúmulo importante de necessidades educacionais: alfabetização, incorporação cada vez mais precoce ao mundo do trabalho, população isolada dos centros urbanos ou impossibilitada de acessar o ensino convencional”. (LITWIN, 2001, p. 39).

Esta modalidade de ensino "[...] é apontada como a forma capaz de conciliar a necessidade de educação continuada com a falta de tempo e as dificuldades cada vez maiores de um profissional estar fisicamente presente em sala de aula”. (CATAPAN, 2009, p. 31).

Segundo Belloni (2009, p. 46), a "Educação a Distância visa prioritariamente a populações adultas que não têm possibilidades de frequentar uma instituição de ensino convencional, presencial, e que têm pouco tempo disponível para dedicar a seus estudos”.

No Decreto 5.622, de 19 de dezembro de 2005 (BRASIL, 2005), em seu artigo primeiro, a Educação a Distância é definida "como uma modalidade educacional na qual a 
mediação didático- pedagógica nos processos de ensino e aprendizagem ocorre com a utilização de meios e tecnologias de informação e comunicação, com estudantes e professores desenvolvendo atividades educativas em lugares e/ou tempos dispersos.”

Muitos autores apresentam diferentes conceitos e visões acerca da educação a distância, porém de um modo geral, pode ser entendida como um método de ensinoaprendizagem que inclui estratégias de ensino aplicando tecnologias de informação, vindo a comprovar que a conquista pelo conhecimento pode ocorrer em tempo real mesmo que aluno e professor possam estar separados fisicamente dentro de um tempo e espaço. Para Moore e Kearsley (2007, p. 2),

Educação a Distância é o aprendizado planejado que ocorre normalmente em um lugar diferente do local do ensino, exigindo técnicas especiais de criação do curso e de instrução, comunicação por meio de várias tecnologias e disposições organizacionais e administrativas especiais.

Atualmente, instituições e governos vêm na educação a distância uma forma eficaz de atendimento de certas necessidades prementes, citadas por Moore e Kearsley (2007, p. 8), que são: acesso crescente a oportunidades de aprendizado e treinamento; oferta urgente de chance de atualização de aptidões; redução de custos educacionais; oferecer apoio para as estruturas educacionais existentes; capacitação educacional; nivelamento de desigualdades existentes entre grupos etários; oferta de educação para públicos-alvo específicos; dar treinamento de emergência para determinado grupo; oferecer uma combinação de educação com trabalho e vida familiar; etc.

Os desafios atuais enfrentados pela educação com a crescente demanda de formação inicial e continuada ao longo da vida, somados à necessidade de preparar profissionais flexíveis, dinâmicos, com abertura para trabalhar em equipe e autonomia para buscar informações e resolver problemas, associados à disseminação do acesso às TICs ou tecnologia digital, ampliaram a oferta de programas de ensino a distância. (LITTO, 2007, p. 105).

Com esta modalidade de ensino, segundo Moore e Kearsley (2007, p. 21), diversas pessoas estão obtendo acesso mais facilmente a mais e melhores recursos de aprendizado do que podiam no passado. Os cursos poderão ser acessados sempre que o aluno desejar e no seu ritmo preferido, a partir de quase todo local. A educação a distância, em termos gerais, permite muitas novas oportunidades de aprendizado para um grande número de pessoas. 
"Educação é o suporte essencial, porque, no lado formal, instrumenta a pessoa com a habilidade crucial de manejar a arma mais potente de combate que é o conhecimento e, no lado político, alimenta a cidadania.” (DEMO, 2007, p. 47).

Em suma, a democratização do ensino proporcionada pela Educação a Distância vem levando qualidade de vida a qualquer pessoa não importando onde esteja.

\section{PROCEDIMENTOS METODOLÓGICOS}

Quanto à natureza esta pesquisa foi aplicada, que segundo Roesch (2009) objetiva entender a natureza humana e a fonte dos problemas humanos. Os resultados deste tipo de pesquisa contribuem para teorias que poderão ser utilizadas na formulação de programas e intervenções para resoluções de problemas.

Considerando o modelo de classificação de pesquisa proposto por Vergara (2013), quanto aos fins, tratou-se de uma pesquisa descritiva onde buscou-se demonstrar a melhoria da qualidade de vida dos alunos egressos do Curso de Graduação em Administração a Distância do polo presencial de Lages/SC após a realização do curso, este ofertado pela Universidade Federal de Santa Catarina. Quanto aos meios a pesquisa foi um estudo de caso onde foi estudado com profundidade e detalhadamente a melhoria de vida destes alunos.

O universo da pesquisa refere-se aos 29 alunos egressos do referido curso, dos quais 17 eram homens e 12 mulheres. De acordo com Vergara (2013) o tipo de amostra selecionada foi não probabilística selecionada por acessibilidade e tipicidade, tendo em vista que a pesquisadora obteve acesso aos dados cadastrais dos alunos com autorização da instituição.

Foi encaminhado, por e-mail, questionário a todos os egressos, buscando desta forma um censo. Foram obtidas 21 respostas, tornando essa a população acessível da pesquisa. $\mathrm{O}$ questionário era composto de 14 questões, sendo 12 fechadas e 2 abertas. O número de questões foi considerado suficiente para analisar se houve melhoria da qualidade de vida dos alunos estudados.

O tratamento dos dados foi iniciado individualmente com a análise das respostas de cada respondente do questionário que foram sintetizadas por questão. Após essa etapa, foi feita uma análise comparativa das respostas obtidas de cada egresso que foram apresentadas por meio de gráficos e tabelas. 


\section{APRESENTAÇÃO E ANÁLISE DOS DADOS}

O Curso de Administração a Distância da Universidade Federal de Santa Catarina foi criado em 2006 “[...] em virtude da necessidade de atender aos estudantes residentes em regiões, sem instituições de ensino superior, como também, profissionais em serviço que necessitam de formação em nível universitário”. (PACHECO, 2010, p. 194). Atualmente, "[...] o curso conta com dez polos de ensino em todo o Estado de Santa Catarina: Araranguá, Criciúma, Laguna, Palhoça, Florianópolis, Tubarão, Joinville, Canoinhas, Lages e Chapecó”. (PACHECO, 2010, p. 194).

A pesquisa foi realizada com alunos egressos do Curso de Administração a Distância do Polo de Apoio Presencial de Lages/SC.

A idade dos respondentes do questionário oscilou de 24 a 52 anos. A literatura evidencia que a maioria dos alunos matriculados no ensino a distância são adultos. São alunos responsáveis, altamente motivados e preocupados com o desempenho profissional, por estas características, capazes de assumir a responsabilidade por seu aprendizado.

Segundo Moore e Kearsley (2007, p. 174),

o adulto é conceituado como uma pessoa com emprego, família e obrigações sociais e, portanto, para um adulto, existem custos ao se matricular em um curso educacional. $\mathrm{O}$ custo pode ser avaliado em dinheiro, porém, o mais importante é que se gasta tempo e esforço.

No início alguns alunos a distância se sentem ansiosos quanto ao estudo, encontrando dificuldades para responder às exigências de autonomia em sua aprendizagem, dificuldades de gestão do tempo, de planejamento e de auto-direção colocadas pela aprendizagem autônoma.

$\mathrm{Na}$ busca por qualidade de vida o indivíduo adulto muitas vezes recorre à educação, pois " [...] educação, expectativa de vida e poder de compra são indicadores fundamentais do desenvolvimento humano". (DEMO, 2007, p. 46).

No questionário foi perguntado o gênero do respondente. Dos 21 respondentes, 13 foram do sexo masculino e 8 do sexo feminino. Isto é, $62 \%$ homens e $38 \%$ mulheres, conforme gráfico 1, a seguir.

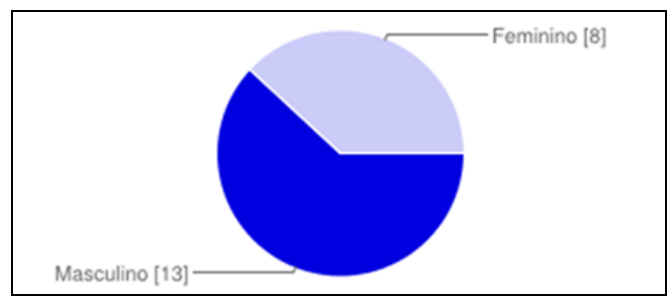

Masculino: $62 \%$

Feminino: $38 \%$

Gráfico 1 Gênero dos respondentes

Fonte: Dados primários (2013). 
Foi indagado ao respondente qual sua formação anterior ao Curso de Graduação em Administração a Distância. O gráfico 2, a seguir, indica que 62\% responderam que tinham ensino médio; $19 \%$ ensino profissionalizante; $14 \%$ graduação e $5 \%$ pós-graduação.

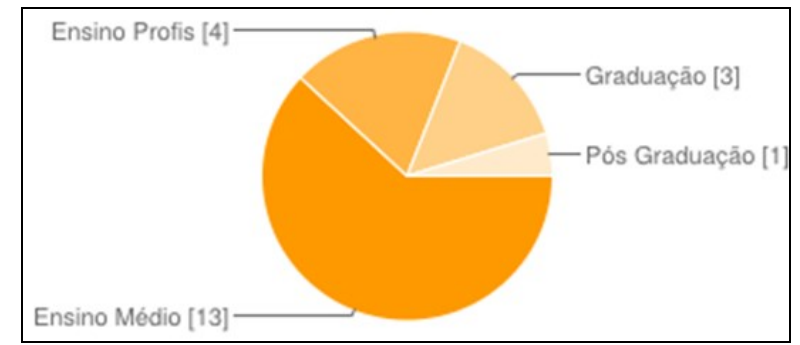

Ensino Médio: 62\%

Ensino Profissionalizante: $19 \%$

Graduação: $14 \%$

Pós-Graduação: 5\%

Gráfico 2 Formação anterior

Fonte: Dados primários (2013).

Segundo Litwin (2001) no contexto educacional o ensino a distância chegou e se consolidou como ferramenta de combate a um acumulado de essenciais necessidades educacionais, como: alfabetização, inclusão prematura ao mundo do trabalho, população isolada dos centros urbanos ou sem possibilidade ao acesso à educação convencional. Com esta modalidade de ensino diversas pessoas estão obtendo acesso mais facilmente a mais e melhores recursos de aprendizado do que podiam no passado.

Foi perguntado aos respondentes qual o ano que concluiu a sua última formação antes da graduação em Administração a Distância. 80,9\% dos respondentes tiveram sua formação anterior há mais de dez anos e somente $19,1 \%$ estiveram em sala de aula a menos de dez anos.

Moore e Kearsley (2007) afirmam que indivíduos adultos veem na educação a distância uma forma de compensação por terem negligenciado, no passado, o ensino médio. Outros se matriculam para conseguir créditos para cursos de ensino superior, muitos o fazem para o aprimoramento de seu conhecimento geral ou como passatempo satisfatório. Porém, a maior motivação que tem levado tantos adultos a procurarem o ensino a distância é a necessidade de desenvolvimento ou aperfeiçoamento para o trabalho.

Se analisarmos conjuntamente os gráficos 3 e 4 que indagava a renda anterior ao ingresso no Curso de Administração a Distância e a renda atual do respondente do questionário, podemos concluir que: 

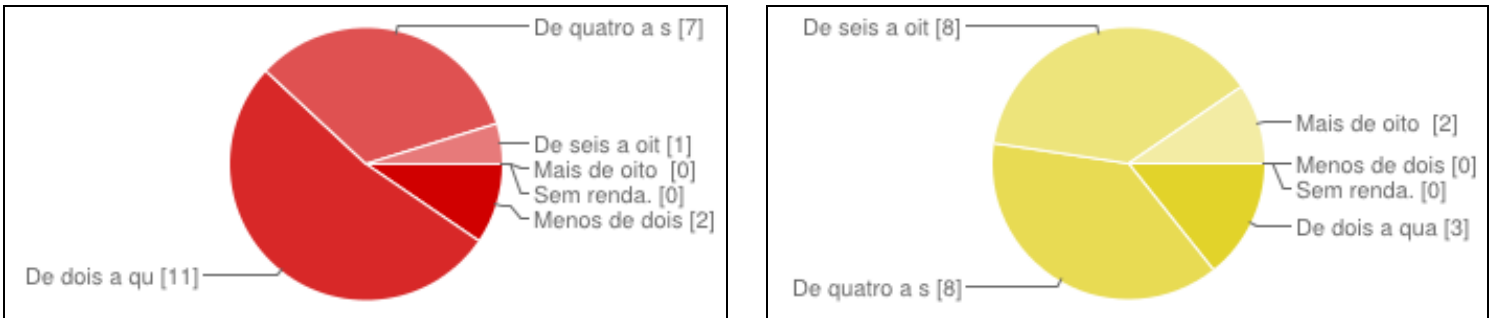

Gráfico 3 Faixa de renda anterior

Fonte: Dados primários (2013).

Gráfico 4 Faixa de renda atual

Fonte: Dados primários (2013).

Tabela 1 Comparação da faixa de renda anterior com a faixa de renda atual

\begin{tabular}{lcccc}
\hline & \multicolumn{2}{c}{ Renda Anterior } & \multicolumn{2}{c}{ Renda Atual } \\
\hline Menos de dois salários mínimos & 2 & $10 \%$ & 0 & $0 \%$ \\
De dois a quatro salários mínimos & 11 & $52 \%$ & 3 & $14 \%$ \\
De quatro a seis salários mínimos & 7 & $33 \%$ & 8 & $38 \%$ \\
De seis a oito salários mínimos & 1 & $5 \%$ & 8 & $38 \%$ \\
Mais de oito salários mínimos & 0 & $0 \%$ & 2 & $10 \%$ \\
Sem renda & 0 & $0 \%$ & 0 & $0 \%$ \\
\hline
\end{tabular}

Fonte: Dados primários (2013).

A conclusão do Curso de Administração a Distância propiciou aumento na faixa salarial da maioria dos respondentes, gerando qualidade de vida. Segundo Silva e Marchi (1997, p. 31),

a importância do trabalho para o bem estar e a saúde das pessoas fica clara ao lembrarmos que é trabalhando que passamos a maior parte de nossa vida enquanto estamos acordados; é no trabalho, ou por meio dele, que realizamos grande parte de nossas aspirações. Compreensível é, pois, o papel relevante do trabalho em nossa vida e o reflexo do restante dela sobre a qualidade do trabalho e o desempenho profissional.

O descontentamento com o trabalho, na visão do trabalhador, pode ser motivado por fatos facilmente identificáveis: “[...] baixos salários, condições insalubres, não gostar, pura e simplesmente, do que faz e, ainda, o que se costuma chamar de "mau ambiente de trabalho", ou seja, conflitos interpessoais". (SILVA; MARCHI, 1997, p. 90).

O ensino a distância está possibilitando ao trabalhador, até em lugares mais remotos, aquisição de conhecimento para enfrentar as necessidades atuais do complexo mundo do trabalho que exige alta escolaridade de seus funcionários.

À medida que se sente valorizado e dignificado ao trabalhar, o empregado não somente se compromete, mas melhora o grau de satisfação em relação a seu trabalho. Reduzse, assim o estresse ocupacional, e melhora sua qualidade de vida. 
O gráfico 5 demonstra as respostas dos respondentes quando indagados sobre a distância da sua residência em relação ao polo presencial.

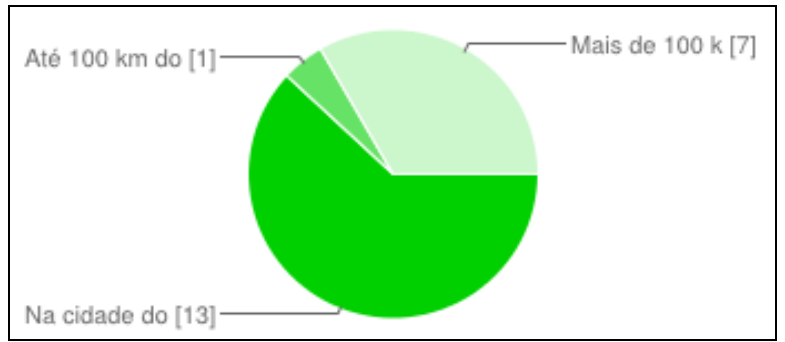

Na cidade polo: $62 \%$

Até $100 \mathrm{~km}$ do polo: $5 \%$

Mais que $100 \mathrm{~km}$ do polo: $33 \%$

Gráfico 5 Distância do aluno em relação ao polo presencial Fonte: Dados primários (2013).

De acordo com o Decreto $n^{\circ} 6.303$ de 12 de dezembro de 2007 (BRASIL, 2007), o polo de apoio presencial é a unidade operacional, no País ou no exterior, para o desenvolvimento descentralizado de atividades pedagógicas e administrativas relativas aos cursos e programas ofertados a distância.

Um dado importante é que 33\% dos respondentes cursaram a graduação a distância a mais de $100 \mathrm{~km}$ do polo presencial e, mesmo com a dificuldade da distância para os encontros presenciais, atingiram seus objetivos na busca por qualidade de vida.

Analisando e comparando o gráfico 6 que demonstra qual o principal objetivo do aluno em relação ao Curso de Graduação em Administração a Distância e o gráfico 7 que mostra se alguma mudança significativa ocorreu em sua vida, podemos concluir que:

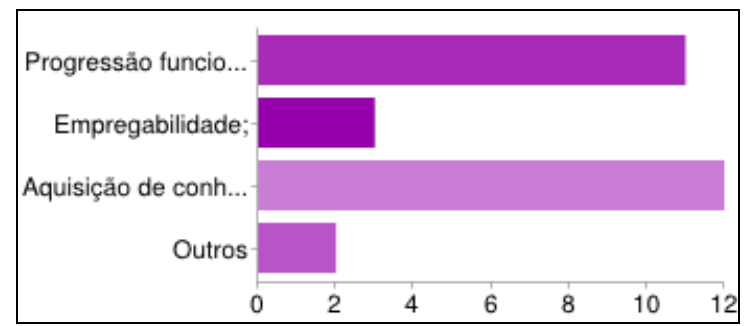

Progressão funcional:

Empregabilidade:

Aquisição de conhecimento:

Outros:

$\begin{array}{cc}11 & 39 \% \\ 3 & 11 \% \\ 12 & 43 \% \\ 2 & 7 \%\end{array}$

Gráfico 6 Objetivos do aluno em relação ao curso Fonte: Dados primários (2013).

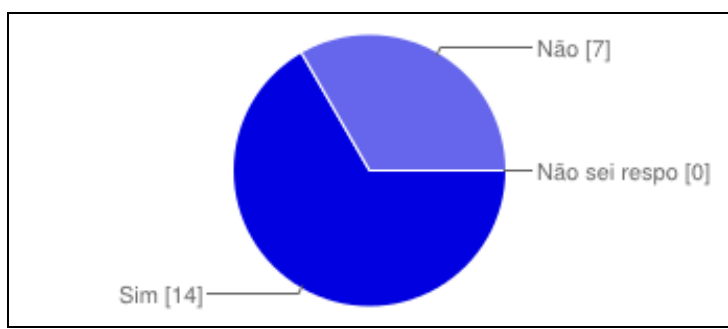

$\begin{array}{lrc}\text { Sim } & 14 & 67 \% \\ \text { Não } & 7 & 33 \% \\ \text { Não sei responder } & 0 & 0 \%\end{array}$

Gráfico 7 Mudanças significativas com a realização do curso Fonte: Dados primários (2013). 
Mudanças significativas ocorreram na vida dos alunos egressos do Curso de Administração a Distância do polo presencial de Lages/SC. Através da aquisição de conhecimento, a maioria, conseguiu trabalho ou uma progressão funcional.

Os profissionais de todas as áreas precisam enfrentar os obstáculos impostos pelo mundo do trabalho através da atualização constante. A Educação a Distância possibilita que o indivíduo possa "[...] conciliar a necessidade de educação continuada com a falta de tempo e as dificuldades cada vez maiores de um profissional estar fisicamente presente em sala de aula”. (CATAPAN, 2009, p. 31).

Quando indagados sobre qual seria a principal vantagem em se fazer um curso de graduação na modalidade a distância, selecionamos a preciosa resposta de um dos respondentes do questionário que, resume a maioria das respostas "vejo na Educação a Distância uma forma de ensino moderna, eficaz, dinâmica, onde o aluno vai atrás do conhecimento e a caminhada depende dele: é uma forma de independência com responsabilidade na forma de estudar. A vitória somente será alcançada nos indivíduos que realmente desejam aprender e que tenham maturidade suficiente para fazer seus horários de estudo. A Educação a Distância exige foco do aluno. Realizei meu sonho de alcançar a graduação num momento da minha vida que não tinha tempo disponível para frequentar uma graduação presencial, a faculdade a distância foi uma oportunidade ímpar e sou grata a UFSC, e a todo corpo docente por ter tido esta oportunidade preciosa em minha vida".

"A educação superior continua sendo um dos principais caminhos para a realização profissional e a libertação do homem na sociedade moderna." (MELO; MELO; NUNES, 2009, p. 301).

A expansão e inclusão social possibilitada pela Educação a Distância “[...] permite às pessoas desenvolverem suas capacidades cognitivas, sociais, emocionais, profissionais e éticas; e viver em sociedade, exercitando sua cidadania plena". (MEC, 2002).

A tabela 2 mostra de forma sintética as conclusões da pesquisa:

Tabela 2 Conclusões da pesquisa

\begin{tabular}{l|l}
\hline Polo presencial & Lages/SC \\
\hline Idade dos respondentes & De 24 a 52 anos \\
\hline & Ensino médio: 13; \\
Formação anterior ao curso de & Ensino Profissionalizante: 4; \\
graduação a distância & Outra Graduação: $3 ;$ \\
& Pós-Graduação: 1 \\
\hline Ano de conclusão da última formação & $\begin{array}{l}80,9 \% \text { dos respondentes tiveram sua formação anterior há } \\
\text { mais de dez anos }\end{array}$ \\
\hline
\end{tabular}




\begin{tabular}{|c|c|}
\hline $\begin{array}{l}\text { Faixa salarial antes de ingressar no } \\
\text { curso }\end{array}$ & $\begin{array}{l}\text { Menos que dois salários mínimos: } 2 \\
\text { De dois a quatro salários mínimos: } 11 \\
\text { De quatro a seis salários mínimos: } 7 \\
\text { De seis a oito salários mínimos: } 1\end{array}$ \\
\hline $\begin{array}{l}\text { Faixa salarial após a conclusão do } \\
\text { curso }\end{array}$ & $\begin{array}{l}\text { Menos que dois salários mínimos: } 0 \\
\text { De dois a quatro salários mínimos: } 3 \\
\text { De quatro a seis salários mínimos: } 8 \\
\text { De seis a oito salários mínimos: } 8 \\
\text { Mais que oito salários mínimos: } 2\end{array}$ \\
\hline $\begin{array}{l}\text { Distância da residência em relação ao } \\
\text { polo presencial }\end{array}$ & $\begin{array}{l}\text { Na cidade do polo: } 13 \\
\text { Até } 100 \mathrm{~km} \text { do polo: } 1 \\
\text { Mais de } 100 \mathrm{~km} \text { do polo: } 13\end{array}$ \\
\hline Mudanças significativas após o curso & $\begin{array}{l}\text { Sim: } 14 \\
\text { Não: } 7\end{array}$ \\
\hline Quais mudanças & $\begin{array}{l}\text { Mudaram de emprego: } 2 \\
\text { Foram promovidos: } 10 \\
\text { Outros mudanças: } 9\end{array}$ \\
\hline
\end{tabular}

Fonte: Dados primários (2013).

Assim, após análise minuciosa dos dados da pesquisa, infere-se que:

a) A conclusão do Curso de Administração a distância propiciou aumento na faixa salarial da maioria dos respondentes, aumentando a qualidade de vida dos mesmos;

b)O ensino a distância está possibilitando ao trabalhador, até em lugares mais remotos, aquisição de conhecimento para enfrentar as necessidades atuais do complexo mundo do trabalho que exige alta escolaridade de seus funcionários;

c) Ocorreram mudanças significativas na vida dos alunos egressos do Curso de Administração a Distância do polo presencial de Lages/SC. Através da aquisição de conhecimento, a maioria, conseguiu trabalho ou uma progressão funcional;

d)Efetivamente comprovou-se que houve aumento da qualidade de vida dos alunos egressos do Curso de Graduação em Administração a Distância do polo presencial de Lages/SC após a realização do curso.

\section{CONCLUSÃO}

A globalização trouxe drásticas mudanças no campo tecnológico, econômico e político-social exigindo dos indivíduos uma educação permanente para atender às demandas desta nova sociedade. A educação se “[...] constituirá provavelmente o melhor senão o único meio de evitar a desqualificação da força de trabalho e a exclusão social de grandes parcelas da população, consistindo num importante fator de estabilidade social”. (BELLONI, 2009, p. 101).

A Educação a Distância aparece a cada dia mais no contexto das sociedades contemporâneas como um sistema de educação extremamente adequado e desejável para atender as novas demandas educacionais decorrentes das mudanças mundiais. 
Os dados obtidos com a pesquisa demonstraram a importância da Educação a Distância na melhoria da qualidade de vida e sua considerável contribuição na democratização do acesso à educação superior.

Sinteticamente constatou-se com a pesquisa que a conclusão do Curso de Graduação em Administração a Distância propiciou aumento na faixa salarial da maioria dos respondentes, aumentando a qualidade de vida dos mesmos. Mudanças significativas ocorreram na vida dos alunos egressos do referido curso, pois através da aquisição de conhecimento, a maioria, conseguiu trabalho ou uma progressão funcional.

Independentemente dos caminhos seguidos em busca da tão sonhada qualidade de vida, a “[...] educação é o suporte essencial, porque, no lado formal, instrumenta a pessoa com a habilidade crucial de manejar a arma mais potente de combate que é o conhecimento e, no lado político, alimenta a cidadania”. (DEMO, 2007, p. 47).

Finalmente, foram cumpridos os objetivos da pesquisa, ou seja, demonstrou-se a importância da Educação a Distância na melhoria da qualidade de vida do indivíduo e sua considerável contribuição para a democratização do acesso à educação superior.

\section{REFERÊNCIAS}

ALMEIDA, Marco Antônio Bettini de; GUTIERREZ, Gustavo Luiz; MARQUES, Renato. Qualidade de vida: Definição, conceitos e interfaces com outras áreas de pesquisa. São Paulo: Edições Each, 2012. Disponível em: <http://each.uspnet.usp.br/edicoeseach/qualidade_vida.pdf $>$. Acesso em: 05 jun. 2013.

BELLONI, Maria Luiza. Educação a Distância. 5 ed. Campinas. Autores Associados, 2009.

BRASIL. Ministério da Educação Superior (SESU). Decreto $\mathbf{n}^{\mathbf{0}}$ 5.622. Disponível em: $<$ https://www.planalto.gov.br/ccivil_03/_Ato2004-

2006/2005/Decreto/D5622compilado.htm>. Acesso em: 12 jul. 2013.

. Ministério da Educação Superior (SESU). Decreto 6.303. Disponível em: $<$ http://www2.mec.gov.br/sapiens/portarias/dec6303.htm>. Acesso em: 12 jul. 2013.

. Ministério da Educação Superior (SESU). Relatório. Brasília, 2002.

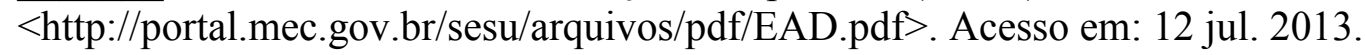

CATAPAN, Araci Hack. et al. Introdução à Educação à Distância. 1. ed e 1 reimpr. Florianópolis: Biologia/EaD/UFSC, 2009.

DEMO, Pedro. Educação e qualidade. 11ª ed. Campinas, SP: Papirus, 2007 - (Coleção Magistério: Formação e Trabalho Pedagógico). 
FINKLER, Pedro. Qualidade de vida e plenitude humana. Petrópolis, RJ: Vozes, 1994.

HEERDT. Mauri. O desafio da qualidade de vida. Jornal Missão Jovem. São Paulo. Disponível em: <http://www.pime.org.br/missaojovem/mjecologiavida.htm>. Acesso em: 31 maio 2013.

HERCULANO, Selene C. A qualidade de vida e seus indicadores. In: Herculano, Selene et al. (Org). Qualidade de vida e riscos ambientais. Niterói: Eduff, 2000. Disponível em: $<$ http://www.ivt-rj.net/ivt/bibli/herculano.pdf>. Acesso em: 15 jun. 2013.

LITTO, Frederic M., FORMIGA, Marcos (Orgs). Educação a Distância: o estado da arte. São Paulo, Pearson, 2009.

LITWIN, Edith. (Org.) Educação a Distância: temas para o debate de uma nova agenda educativa. Porto Alegre: Artmed. 2001.

MELO, Pedro Antônio de; MELO, Michelle Bianchini de; NUNES, Rogério da Silva. Educação à Distância como Política de Expansão e Interiorização da Educação Superior no Brasil. Revista de Ciências da Administração, Florianópolis, v. 11, n. 24, p. 278-301, maio/agosto 2009.

MOORE, Michael; KEARSLEY, Greg. Educação a distância: Uma Visão Integrada. [Tradução Roberto Galman]. São Paulo: Thomson Learning, 2007.

PACHECO, Andressa Sasaki Vasques. Evasão e permanência dos estudantes de um Curso de Administração do Sistema Universidade Aberta do Brasil: uma teoria fundamentada em fatos e na gestão do conhecimento. 2010. 298 f. Tese (Doutorado) - Curso de Pósgraduação em Engenharia e Gestão do Conhecimento, Universidade Federal de Santa Catarina, Florianópolis, 2010.

ROESCH, Sylvia Maria Azevedo. Projetos de estágio e de pesquisa em Administração: guia para estágios, trabalho de conclusão, dissertações e estudos de caso. 3.ed. São Paulo: Atlas, 2009.

SIMÕES, Regina. (Qual)idade de vida na (Qual)idade de vida. In: MOREIRA, Wagner Wey (Org.). Qualidade de vida: Complexidade e Educação. Campinas, SP: Papirus, 2001.

SILVA, Marco Aurélio Dias da; MARCHI, Ricardo de. Saúde e qualidade de vida no trabalho. São Paulo: Best Seller, 1997.

SILVA, Ozires. A Educação sem distância. In. MELO, Maria Tais de (Org.) EAD: educação sem distância. São Paulo: Laborciência, 2007.

VERGARA, Sylvia Constant. Projetos e Relatórios de Pesquisa em Administração. 14 ${ }^{\mathrm{a}}$ Ed. São Paulo: Atlas, 2013. 